\title{
Temporary Penial urethral stent placement procedure as a treatment of penile urethral obstruction in Intact Tom Cats
}

\section{Houssam H. Abdelrehim, Reham N. Elsamanody, Asmaa A. Abdelmotaleb}

Surgery Department, Cats \&Dogs Veterinary Hospital, Shorouk City, Cairo, Egypt

\section{ARTICLE HISTORY}

Received: 12.09 .2021

Revised: 12.10 .2021

Accepted: 12.10 .2021

Correspondence to: Houssam $\mathrm{H}$.

Abdelrehim; Tel: +201050646334

Email: samrehim2000@gmail.com

\begin{abstract}
Objective: The treatment of penile urethral obstruction in Tom Cats with no response to catheterization by placing a temporary urethral stent to avoid going through perineal urethrostomy or preputial urethrostomy.

Design: Case Study (April 2015 - June 2021)

Animals: 14 Intact Tom Cats.

Procedures: In the current study, fourteen male cats with obstructed urethras with no response to catheterization were subjected to intervention using a temporary urethral stent. Cases were observed for 10 days postoperative, monitoring blood creatinine level after operations and cases had follow up visits for a year on monthly basis for checkup the subjects' lifestyle.

Results: The procedure was successfully performed, and cats restored their normal lifestyle. Unfortunately, $2 / 14$ cases died at days 9 and 11 after the operation. Both cases show no decrease in blood creatinine levels at day 2 and day 4 after operation as other subjects did.

Conclusion and clinical relevance: Temporary penile Urethral stent provided a fast less complicated solution for intact tom cats from urine retention with subjects going back to their normal lifestyle after 10 days, avoiding going through perineal urethrostomy or preputial urethrostomy. Temporary Urethral stent could be considered as a treatment for penile urethral obstruction before going to perineal urethrostomy or preputial urethrostomy for treatment penile urethral obstruction.
\end{abstract}

Key words: Urethral stent, cat, Treatment, Urethral obstruction

\section{INTRODUCTION}

Urological illnesses are commonly seen with cats at veterinary clinics or Hospitals, involving over $7 \%$ of the feline case load [1]. A study examining obstructed cats had $59 \%$ of cases with urethral plugs and $12 \%$ with uroliths. and the other $29 \%$, with no specific cause [2]. on the other hand, a different study with non-obstructed cats have urolithiasis in approximately $13 \%$ of cases and the underlying cause of urinary tract symptoms could not be identified in about $64 \%$ of its cases [3]. If causes cannot be identified, idiopathic lower urinary tract disease always considered. Urethral calculi can result in either a complete or partial urethral obstruction which is more frequently diagnosed in male cats more than female cats. mostly at the junction of the intrapelvic and penile urethra in male cats. [4]. Patients could develop post renal uremia and hyperkalemia, depression, and vomiting. also, urinary bladder rupture [4]. Where there is no response to catheterization with penile urethral obstruction, veterinary surgeons normally go to perineal urethrostomy technique in which the urethra was sutured to the perineal skin, with castration and penis amputation [5]. Perineal urethrostomy complication rates vary from 13 to $25 \%$ and from 20 to $42 \%$ in the short and the long term, respectively, with mortality rates of up to $24 \%$ [6].

All over the years it has been reported that (>97\%) of stones that are submitted for analysis had been removed from the lower urinary tract specifically the penile urethra, causing obstruction in male cat, which they were Struvite stones by $48.6 \%$ of the cases and Calcium oxalate stones by $40.8 \%$ and Urate in $4.9 \%$.[7].

This current study was delineated to demonstrate an alternative technique using urethral stent in order to maintain normal lifestyle and sexual activities of tom cats.

\section{MATERIALS AND METHODS}

\subsection{Subjects}

Fourteen male cats with obstructed urethras with no response to catheterization were used in the current study after having an informed written consent from the owners of the animals was taken. All Institutional and National Guidelines for the care and use of animals were followed.

Seven Persian, Flufy 3 years 3.1 KG Body weight, Snowball 2 years, 4 KG Body weight. Tayeb 3 years $2.5 \mathrm{KG}$ Body weight, Ricko 1 year 2.8 KG Body weight, Meshmesh 5 years 7.2 KG Body weight, Icey 7 years $4.5 \mathrm{KG}$ Body weight and Lilo 3 years, 5.3KG body weight. 3 Egyptian Mao, Gamal 5 years $2.6 \mathrm{KG}$ Body weight, Besbes 2 years $3 \mathrm{KG}$ Body weight, and Sultan 1.5 years 2 KG Body weight. 3 Mix breads, Bondouq 2 years 3.7 KG Body weight, Chixy 4 years 3.7 KG Body weight and Casper 1 year 2 KG Body weight. and 1 Siamese with no name at the age of 1 year at operation time 3 KG Body weight (Table 1).

\subsection{Anesthesia}


Atropine sulphate at a dose of $1 \mathrm{ml} / 9 \mathrm{~kg}$ subcutaneously, followed by i.v. administration of Ketam (ketamine hydrochloride, of Eipico pharmaceuticals, at a dose of 11 $\mathrm{mg} / \mathrm{kg}$, using KRUUSE Moduflex Coaxial anaesthesia machine. Anesthesia was maintained using Forane (isoflurane, Abbot pharmaceuticals, 1-3 \%) with oxygen flow at $20 \mathrm{ml} / \mathrm{kg} / \mathrm{min}$.

\subsection{Urethrotomy}

Midline incision was made $5 \mathrm{~mm}$ below the glans using No 15 surgical blade until just before the bulbus glandis including the prepuce. (Figure 1- A). then the pulling of the outer skin layer laterally for better vision of the retractor preputial muscle as it shows in (Figure 1, B), This is followed by releasing the surrounding connective tissue from the urethra. The retractor preputial muscle is retracted laterally to visualize the urethra (Figure $1-C$ ). The urethra is then incised with a No. 11 blade over the stones (Figure 1- D). The stones are removed, and urinary catheter is placed inside the urethra, (Figure 2 -A) shows holding the tip of the catheter gently with a mosquito forceps and takes it towards the caudal opening of the urethra. While (Figure 2-B) shows the tip of catheter goes inside the caudal opening of the urethra. Then pull another part of the catheter $(1 \mathrm{~cm})$ gently and take it towards the caudal opening of the urethra as it shows in (Figure 2-C), at (Figure 2-D) the insertion of another $(1 \mathrm{~cm})$ of catheter in the caudal opening of the urethra.

The urethrotomy is then closed with 5-0 Vicryl absorbable sutures in a simple continuous pattern using the magnifying loop glasses, to easily identify the edges of the urethra. Figure 3-A identifies the edges of the urethra, and the arrow is pointed at the edge of the urethra. while at (Figure 3-B) start with the first stitch using 5/0 Vicryl from the top of the incision. (Figure $3-\mathrm{C})$ shows that after $1^{\text {st }}$ stitch, stretching of the penis upward to narrow the edges of the urethra for a better vision of the site. The arrow is pointed at the edges of the urethra. At (Figure 3D) will carry Continues stitches till the end of the incision.

The corpus spongiosum surrounding the urethra as well as the connective tissue and the Tunica Albuginea were stitched using 5/0 Vicryl (Figure $4-A$ ) shows the starting to stitch the thin layer of corpus spongiosum surrounding the urethra as well as the connective tissue and the Tunica Albuginea. While (Figure 4-B, C, D) shows the continues pattern that will close the rest of those layers.

Skin and prepuce were sutured with simple continues stitches from caudal towards cranial all the way up using $3 / 0$ Vicryl, as it shows (Figures 5 -A) starting of $1^{\text {st }}$ stitch from right edge of prepuce skin using 3/0 Vicryl. (Figure 5-B) shows the insertion of needle to the left edge for the $1^{\text {st }}$ stitch. At (Figure $5-C)$ starting $2^{\text {nd }}$ stitch from right edge. While at (Figure 5-D) insertion of needle to the left edge of prepuce.

\subsection{Postoperative care}

Patients were hospitalized for 10 days; Cefotaxime $125 \mathrm{mg}$ IM injection were administered every 12 hours to all patients for 7 days as well as Gentamycin topical antibiotic cream was applied at the stitches for 10 days after operation. The Patients wore E. collars for the 10 days. Intravenous fluids were administered as well as Halphaperol $0.4 \mathrm{mg}$ tablet twice per day to dissolve stone residues. Monitoring of creatinine within the $1^{\text {st }}$ week was conducted.

At (Figure 6-A) will see the healing after 2 days, while at (Figure 6-B) could see the healing after day 4. Stent was removed and subjects were dismissed from clinic 10 days after operation with normal lifestyle and normal urination.

\subsection{Follow up}

12 Follow up visits for a year on monthly basis for checkup the subjects' lifestyle, site of the operation and their diet change has been carried out.

\subsection{Statistical analysis}

Statistical analysis was performed using the International Renal Interest Society (IRIS) staging system for feline chronic kidney disease, the mean creatinine level in the pre operation was significantly high than both at two days $\mathrm{PO}$ and four days post operation $(P<0.001)$. Meanwhile, the creatinine level at two days $\mathrm{PO}$ differs from that at four days $\mathrm{PO}(\mathrm{P}<0.05)$ (Table1, Figure 7). In the current study, 5 cases were in stage 4 at the time of the operation (Table 1, Figure 7). The creatinine levels of the two dead cases did not fall. Three cases showed decrease in the creatinine levels to nearly half $(2.9 \mathrm{mg} / \mathrm{dl}, 3.7 \mathrm{mg} / \mathrm{dl}$, and $2.4 \mathrm{mg} / \mathrm{dl}$ ) of the pre-operative levels at day 4 after the operation (Table 1, Figure7). six cases were in stage 3 at the time of the operation, two cats went down to (Stage2), while four of them went down to stage 1 below $1.58 \mathrm{mg} / \mathrm{dl}$ at day 4 PO (Table 1, Figure 7). There were three cases in stage 2 at time of operation, two of them remained in stage 2 . While one moved to stage one by going down from $2.8 \mathrm{mg} / \mathrm{dl}$ to $1.3 \mathrm{mg} / \mathrm{dl}$. (Table 1, Figure 7).

\section{RESULTS AND DISCUSSION}

Fourteen intact male cats with obstructed urethras with no response to catheterization had subjected to bladder rupture, postrenal uremia and hyperkalemia underwent this procedure starting from April 2015 until June 2021. Surgical procedure was successful with all fourteen cases, as urethral stent was successful in treating obstructed penile urethra and maintain urine flow normally and subjects restored their normal lifestyle 10 day after the operation. Figure 8 shows Flufy, (Persian Cat had his procedure at April 2015) after 6 years with no scar and perform his normal lifestyle

Times of urine retention before operation ranged from one to four times, while blood creatinine levels varied between 2.5 to $10.28 \mathrm{mg} / \mathrm{dl}$ (Table 1 ). 


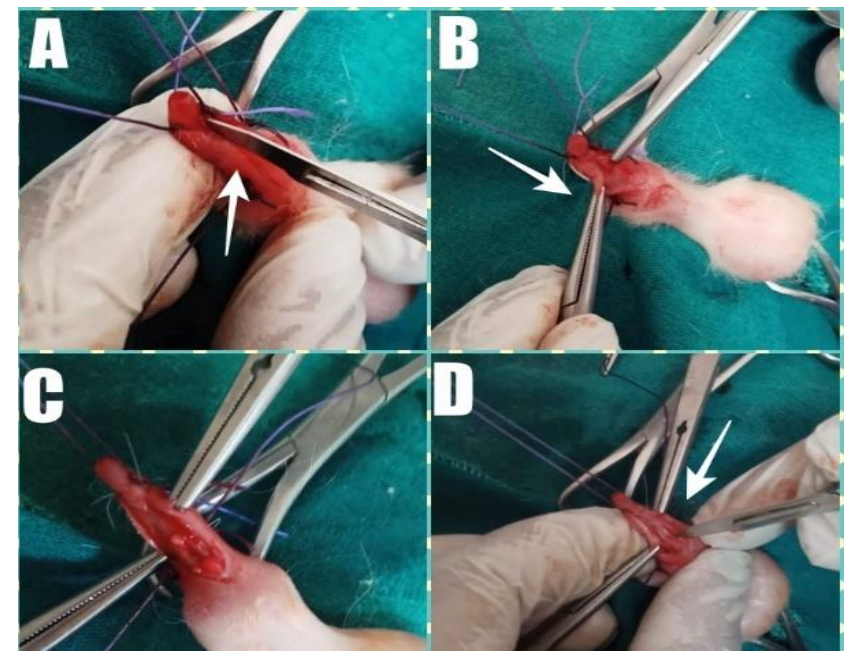

Figure 1. Icey is A 7 years Persian male tomcat with penile urethral obstruction. The incision of the skin, prepuce and urethra. a) incision was made $5 \mathrm{~mm}$ below the glans using $N_{0} 15$ surgical blade until just before the Bulbus Glandis including the prepuce. b) pull outer skin layer laterally for better vision of the retractor preputial muscle. c) The retractor preputial muscle is retracted laterally to visualize the urethra. d) The urethra is then incised with a No.11 blade over the stones.

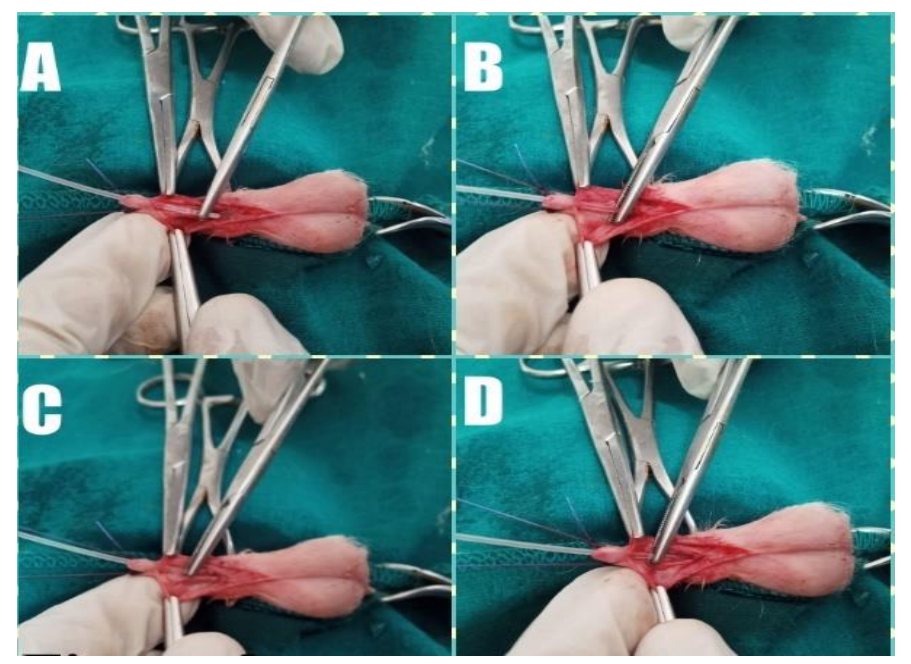

Figure 2. Placing of catheter in the penile urethra: a) holding the tip of the catheter gently with a mosquito forceps and takes it towards the caudal opening of the urethra. b) tip of catheter goes inside the caudal opening of the urethra. c) pull another part of the catheter $(1 \mathrm{~cm})$ gently and take it towards the caudal opening of the urethra. d) insertion of another $(1 \mathrm{~cm})$ of catheter in the caudal opening of the urethra.

Two Persian Cats had died later. Both showed urine retention for the fourth time with Ca Oxalate stones. The first case, a 5-years-old Male Cat, showed a blood creatinine level $7.8 \mathrm{mg} / \mathrm{dl}$ at time of operation, had died 9 days after the operation. The second case is a 3-years-old Male Cat with blood creatinine level $10.28 \mathrm{mg} / \mathrm{dl}$ had died 11 days after the operation. Both cases show no decrease in blood creatinine levels at day 2 and day 4 after operation (Table 1 ).

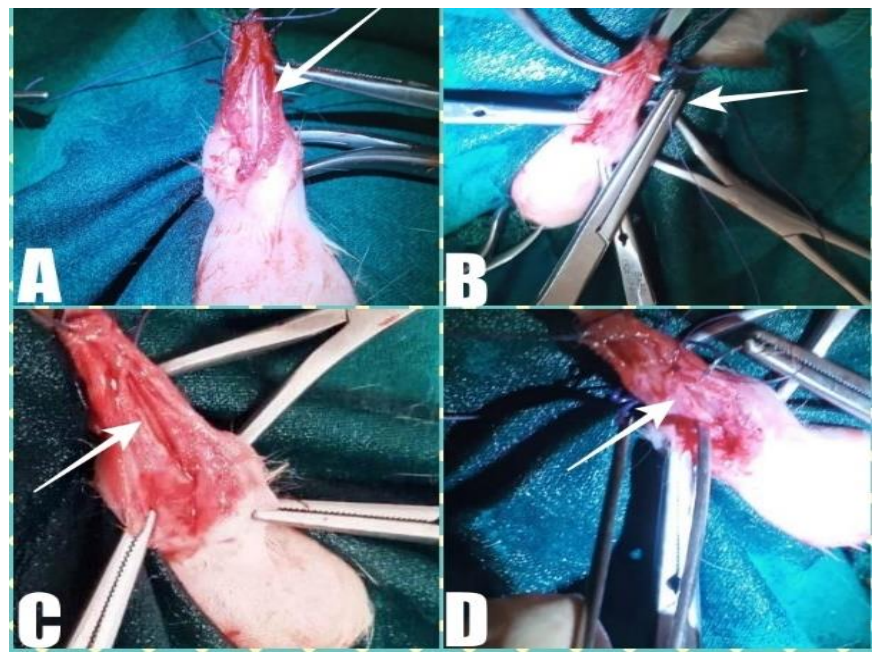

Figure 3. Urethral anastomosis of penile urethra: a) using the magnifying loop glasses with the light on to identify the edges of the urethra, arrow pointed at the edge of the urethra. ib) First stitch using 5/0 Vicryl from the top of the incision. c) after $1^{\text {st }}$ stitch stretching of the penis upward to narrow the edges of the urethra for a better vision of the site. The arrow is pointed at the edges of the urethra. d) Continues stitches till the end of the incision.

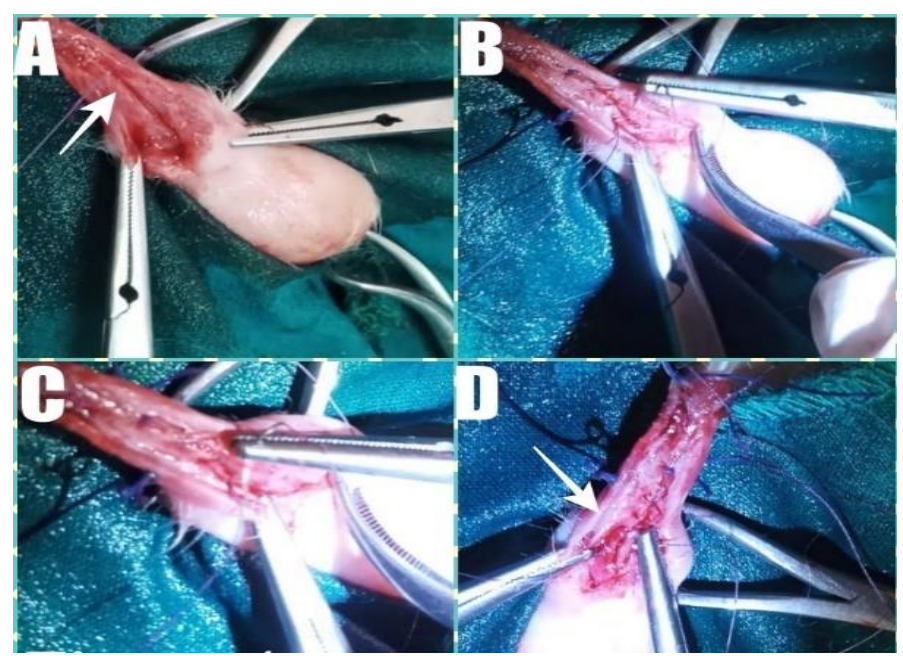

Figure 4. Stitching of corpus spongiosum, connective tissue and Tunica Albuginea. starting to stitch the thin layer of corpus spongiosum surrounding the urethra as well as the connective tissue and the Tunica Albuginea using 5/0 Vicryl.b, c, d) continues pattern will close the rest of those layers.

The Temporary penile urethral stent placement procedure cleared the blockage of penile urethra, relieved urine retention, insured the healing of the urethra normally and blood creatinine levels were noticeably decreased for 12 living cases post-operative.

The site of surgery for Temporary urethral stent placement is different than the most common Perineal urethrostomy and preputial urethrostomy procedures as the corpus spongiosum surrounding the urethra consists of plexus of large caverns tissue surrounded by connective tissue [9], so the incision was made $5 \mathrm{~mm}$ after the glans penis, as in (Figure 1-A). while cross section of the penis body showed three distinct layers of 
connective tissue, the first layer under the skin is thick tunica albuginea, the second layer is well vascular innervated connective tissue. [9] The third layer of dense irregular connective tissue which sent trabeculae to form the network of cavernous tissue of single corpus cavernosum. In (Figure 1-C) show the releasing of the surrounding connective tissue from the urethra, the corpus cavernosum has cavernous tissue with adipose connective tissue and supported by collagen bundles [9]. The urethra located ventrally to the corpus cavernosum and surrounded by thin distinct layer of corpus spongiosum, that is where the incision made as in (Figure 1-D) Ventrally to the urethra there was a thick bundle of smooth muscle of retractor muscle. Which is retracted laterally to visualize the urethra (Figure $1-C$ ) the penis skin showed no hair follicles which is clear at (Figure 1-A) during the incision or at (Figure 4-B, C,D). The root of penis was composed of two crura, each has composed of thick bundles of skeletal muscle housed the secretory units of bulbourethral gland [9].

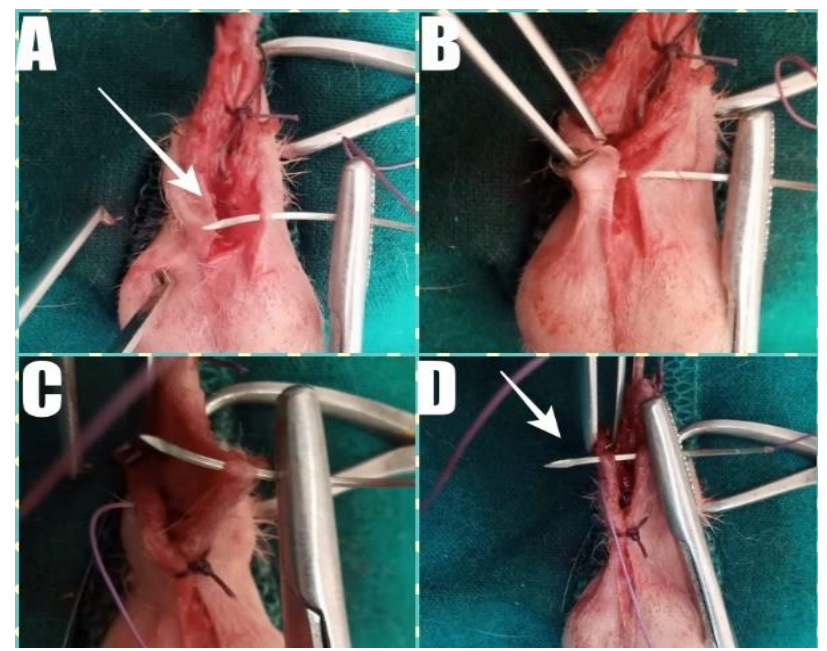

Figure 5. Stitching penile skin and prepuce: a) starting of $1^{\text {st }}$ stitch from right edge of prepuce skin using $3 / 0$ Vicryl. b) insertion of needle to the left edge for the $1^{\text {st }}$ stitch. c) starting $2^{\text {nd }}$ stitch from right edge. d) insertion of needle to the left edge of prepuce.

On the other hand, Perineal urethrostomy create permanent urethral opening between the pelvic urethra and the perineal skin, indicated in cases with no response to catheterization [8] which has reports of complication rates 13$25 \%$ and $20-42 \%$ in the short and long term respectively. as urinary tract infection, subcutaneous urine leakage, urinary incontinence, and perineal hernia. [10-14] also bacterial cystitis $[12,15-16]$. and the risk of the urethral branches of the pudendal nerve could be injured during surgery [17-19]. None of these complications were reported in the current Temporary urethral stent placement procedure. Also, Perineal urethrostomy mortality rate was reported to be up to $24 \%$ [8]. while, in the current study 2 out of 14 cats (entering the study with stage 4 renal failure) died after the operation in the current study (14\%). on the other hand, prepubic urethrostomy is a technique deals with a failed perineal urethrostomy, irreparable injury of the intrapelvic urethra or congenital narrowing of the intrapelvic urethra,[8]. is associated with significant complications as urine scalding, skin necrosis and urinary incontinence [20-23]. No records of any of such side effects with any of the current study subjects. The possible cause of death for the two tom cats died at this study at day 9 and day 11 after the operation is renal failure as both were in stage 4 renal failure and their creatinine failed to decrease after operation and both cases had experienced the $4^{\text {th }}$ time of urine retention before operation.

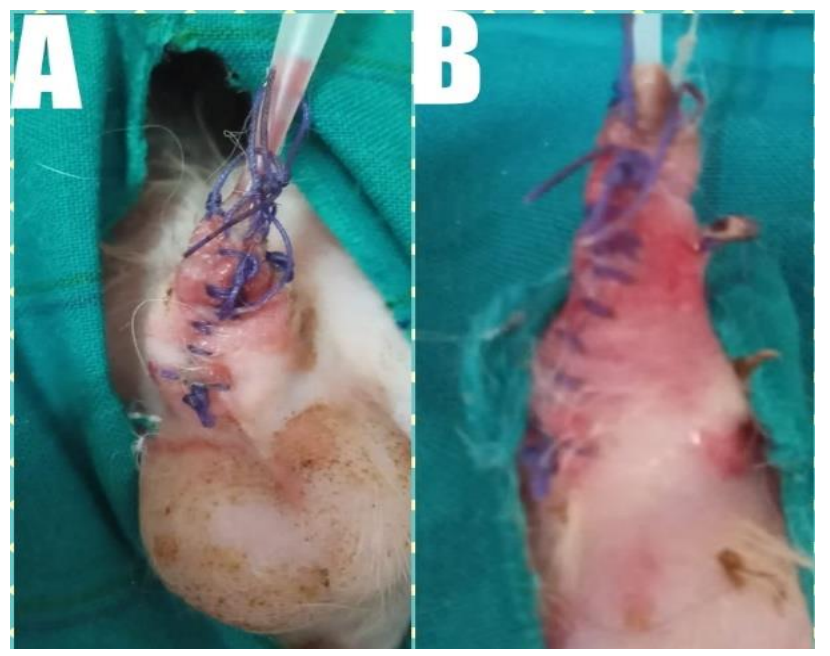

Figure 6 . The healing of the outer skin layer after the operation. a) shows the healing after 2 days of the operation. b) shows the healing after 4 days.

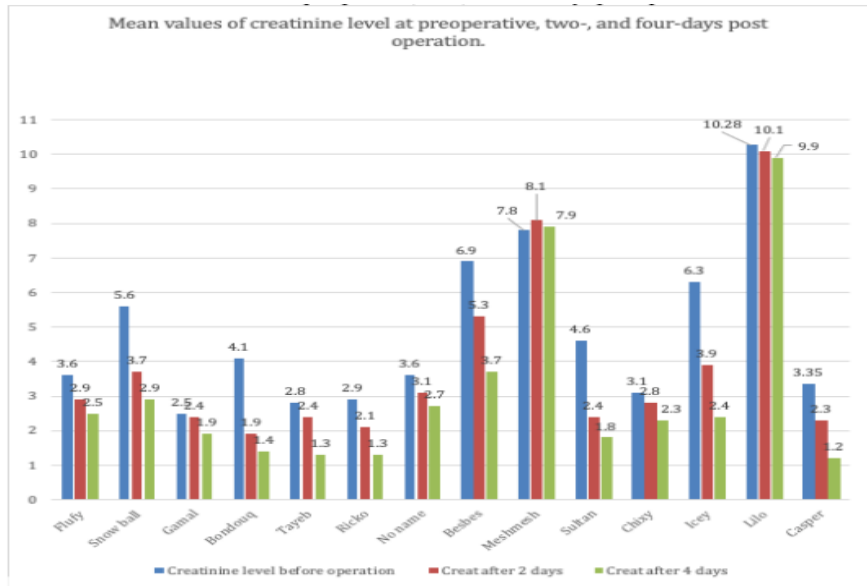

Figure 7. Mean values of creatinine level at preoperative, two-, and four-days post operation. Notice The creatinine levels of the two cases did not fall. And 12 cases went down.

The Temporary penile urethral stent placement procedure treated the obstruction in all cases, and they did not have to go through perineal urethrostomy nor prepubic urethrostomy to relieve the urine retention, as this procedure succeeded in keeping all males intact and no short term nor long term complications was noticed with 12 living subjects. Although 
dietary change is very important to prevent the formation of stones once again.

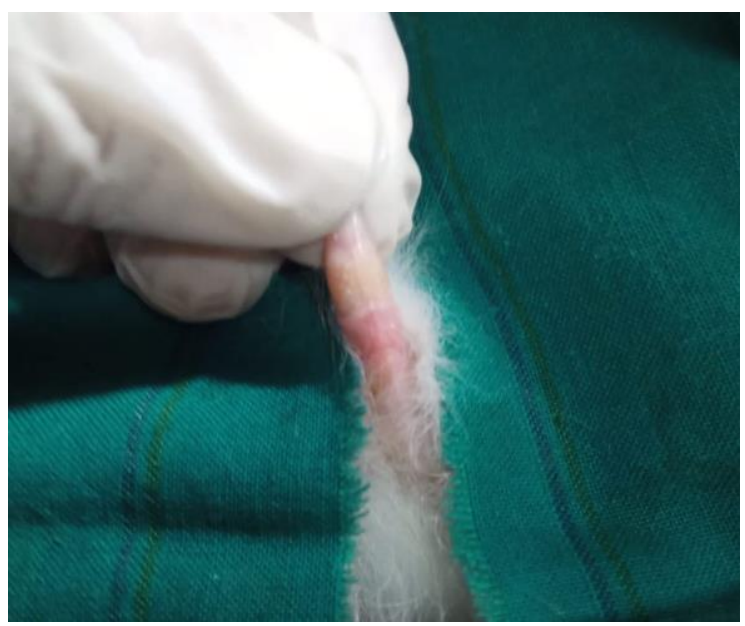

Figure 8. Flufy after 6 years of the operation: Flufy is a Persian male had his operation at April 2015, at this photo showing no scar at the site of the procedure.

Table 1. Demographic data of cats with information type of stones, creatinine level as well as Details.

\begin{tabular}{|c|c|c|c|c|c|c|c|c|c|c|}
\hline Ref No & Name & $\begin{array}{l}\text { Date of } \\
\text { Operation }\end{array}$ & Breed & $\begin{array}{l}\text { Age at } \\
\text { Operation }\end{array}$ & $\begin{array}{l}\text { Times of } \\
\text { urine } \\
\text { retention }\end{array}$ & $\begin{array}{l}\text { Creatinine } \\
\text { level before } \\
\text { operation } \\
(\mathrm{mg} / \mathrm{dl})\end{array}$ & $\begin{array}{l}\text { Type of } \\
\text { Stone }\end{array}$ & $\begin{array}{l}\text { Creat after } \\
2 \text { days } \\
\mathrm{mg} / \mathrm{dl}\end{array}$ & $\begin{array}{l}\text { Creat } \\
\text { after } 4 \\
\text { days } \\
(\mathrm{mg} / \mathrm{dl})\end{array}$ & Out come \\
\hline 494 & Flufy & 04/2015 & Persian & 3 years & $1 s t$ & 3.6 & Ca oxlt & 2.9 & 2.5 & A live \\
\hline 2805 & Snowball & 06/2015 & Persian & 2 years & $3 r d$ & 5.6 & Ca oxlt & 3.7 & 2.9 & A live \\
\hline 2428 & Gamal & $12 / 2015$ & Mao & 5 years & $1 s t$ & 2.5 & Ca oxlt & 2.4 & 1.9 & A live \\
\hline 2986 & Bondouq & $05 / 2016$ & Mix & 2 years & $1 s t$ & 4.1 & Ca oxlt & 1.9 & 1.4 & A live \\
\hline 2795 & Tayeb & $12 / 2016$ & Persian & 3 years & 2nd & 2.8 & Ca oxlt & 2.4 & 1.3 & A live \\
\hline 1849 & Ricko & 08/2017 & Persian & 1 year & $1 s t$ & 2.9 & Struvite & 2.1 & 1.3 & A live \\
\hline 3435 & No name & $10 / 2018$ & Siamese & 1 year & $1 s t$ & 3.6 & Ca oxlt & 3.1 & 2.7 & A live \\
\hline 3840 & Besbes & $04 / 2019$ & Mao & 2 years & $3 r d$ & 6.9 & Struvite & 5.3 & 3.7 & A live \\
\hline 2898 & Meshmesh & $12 / 2019$ & Persian & 5 years & 4th & 7.8 & Ca oxlt & 8.1 & 7.9 & Died at day 9 \\
\hline 2517 & Sultan & $06 / 2020$ & Mao & 1.5 years & 2nd & 4.6 & Struvite & 2.4 & 1.8 & A live \\
\hline 3558 & Chixy & $12 / 2020$ & Mix & 4 years & 2nd & 3.1 & Ca oxlt & 2.8 & 2.3 & A live \\
\hline 4883 & Icey & $04 / 2021$ & Persian & 7 years & 2nd & 6.3 & Ca Oxlt & 3.9 & 2.4 & A live \\
\hline 2854 & Lilo & $06 / 2021$ & Persian & 3 years & 4 th & 10.28 & Ca oxlt & 10.1 & 9.9 & $\begin{array}{l}\text { Died at day } \\
11\end{array}$ \\
\hline 4907 & Casper & $06 / 2021$ & Mix & 1 year & $1 \mathrm{st}$ & 3.35 & Ca oxlt & 2.3 & 1.2 & a live \\
\hline
\end{tabular}

\section{Conclusion}

The Temporary penile urethral stent placement procedure should be considered as a promising approach for the treatment of penile urethral obstruction with no response to catheterization avoiding going through perineal urethrostomy or preputial urethrostomy, saving tom cats all complications reported with the two procedures.

The Temporary urethral stent placement procedure provided a fast less complicated solution for intact tom cats from urine retention with subjects going back to their normal lifestyle after 10 days.
Tom cats with penile urethral obstruction has a good chance to experience normal life after The Temporary penile urethral stent placement procedure specially with diet change.

\section{Acknowledgement}

Authors thank Faculty of Veterinary Medicine Mansura University for help and support; Professor Ahmed S. Abdelmenem, Faculty of Veterinary Medicine Beni Suif University.Staff of Cats \& Dogs Veterinary Hospital Shorouk city, Cairo, Egypt.

\section{Conflict of interest statement}


The authors declare no conflict of interest.

\section{Animal ethics committee permission}

Fourteen male cats with obstructed urethras with no response to catheterization were used in the current study after having an informed written consent from the owners of the animals was taken. All Institutional and National Guidelines for the care and use of animals were followed.

\section{Authors' contribution}

Houssam $\mathrm{H}$. Abdelrehim had planned for the case study carried out the surgical procedures, follow up over postoperative care and lab analysis; Reham N. Alsamanody had assisted in all surgical procedures, carried out postoperative care for all cases; Asmaa A. Abdelmoteleb assisted in all surgical procedures carried out all lab analysis.

\section{REFRENCES}

[1]. Osborne, C. A., J. M. Kruger \& J. P. Lulich, 1995. Feline lower urinary tract diseases. In: Textbook of Veterinary Internal Medicine, eds S. J. Ettinger \& E. C. Feldman, W. B. Saunders, Philadelphia, pp. 18051832.

[2] Osborne, C. A., J. J. Sanna, L. K. Unger, C. W. Clinton \& M. P. Davenport, 1989. Analyzing the mineral composition of uroliths from dogs, cats, horses, cattle, sheep, goats and pigs. Veterinary Medicine, 84, 750-764.

[3] Buffington, C. A., D. J. Chew, M. S. Kendall, P. V. Scrivani, S. S. Thompson, I. I. Blaisdell \& R. F. Woodsworth, 1997. Diet therapy in cats with lower urinary tract disorders. Veterinary Medicine, 99, 626-630.

[4] Monnet, Eric,. Kyles, Andrew,. small animal soft tissue surgery. John Wiley \& Sons, 2012. https://doi.org/10.1002/9781118997505

[5] Saroglu, M., Acar, S. E., \& Duzgun, O. Urethrostomy done using the anastomosis technique of the prepuce mucosa to the pelvic urethra in cats with penile urethral obstruction. Veterinární Medicína, 2003, 48(8), 229. https://doi.org/10.17221/5774-VETMED

6. Ruda $L$ and Heiene R. Short- and long-term outcome after perineal urethrostomy in 86 cats with feline lower urinary tract disease. J Small Anim Pract 2012; 53: 693-698. https://doi.org/10.1111/j.17485827.2012.01310.x

[7] Osborne, C. A., Lulich, J. P., Kruger, J. M., Ulrich, L. K., \& Koehler, L. A. (2009). Analysis of 451,891 canine uroliths, feline uroliths, and feline urethral plugs from 1981 to 2007: perspectives from the Minnesota Urolith Center. Veterinary Clinics of North America: Small Animal Practice, 39(1), 183-197. https://doi.org/10.1016/j.cvsm.2008.09.011

[8] Wilson GP and Harrison JW. Perineal urethrostomy in cats. J Am Vet Med Assoc 1971; 159: 1789-1793.

[9] Dawood, Mohammed, S. Histological features of penis in indigenous tom cat. Indian Journal of Natural Sciences, 8(47), 13720-13729.

[10] Carbone MG (1965) Perineal urethrostomy in the male cat: a report on twenty cases. Journal of the American Veterinary Medical Association 146: 843-853.

[11] Sackman JE, Sims MH, Krahwinkel DJ (1991) Urodynamic evaluation of lower urinary tract function in cats after perineal urethrostomy with minimal and extensive dissection. Veterinary Surgery 20: 55-60. https://doi.org/10.1111/j.1532-950X.1991.tb00306.x

[12] Osborne CA, Caywood DD, Johnston GR et al. (1996) Feline perineal urethrostomy: a potential cause of feline lower urinary tract disease. Veterinary Clinics of North America. Small Animal Practice 26: 535-549. https://doi.org/10.1016/S0195-5616(96)50083-5
[13] Agrodnia MD, Hauptman JG, Stanley BJ, Walshaw R (2004) A simple continuous pattern using absorbable suture for perineal urethrostomy in the cat: 18 cases (2000-2002). Journal of the American Animal Hospital Association 40: 479-483. https://doi.org/10.5326/0400479

[14]. Bass M, Howard J, Gerber B, Messmer M (2005) Retrospective study of indications for and outcome of perineal urethrostomy in cats. Journal of Small Animal Practice 46: 227-231. https://doi.org/10.1111/j.17485827.2005.tb00314.x

[15] Osborne CA, Caywood DD, Johnston GR, Polzin DJ, Lulich JP, Kruger JM (1991) Perineal urethrostomy versus dietary management in prevention of recurrent lower urinary tract disease. Journal of Small Animal Practice 32: 296-305. https://doi.org/10.1111/j.1748-5827.1991.tb00935.x

[16] Griffin DW, Gregory CR (1992) Prevalence of bacterial urinary tract infection after perineal urethrostomy in cats. Journal of the American Veterinary Medical Association 200: 681-684.

[17] Gregory CR (1984) Electromyographic and urethral pressure profilometry. Clinical application in male cats. Veterinary Clinics of North America. Small Animal Practice 14: 567-574. https://doi.org/10.1016/S01955616(84)50062-X

[18] Gregory CR, Holliday TA, Vasseur PB, Bruhl-Day RA, Parker HR, McNeal D (1984) Electromyographic and urethral pressure profilometry: assessment of urethral function before and after perineal urethrostomy in cats. American Journal of Veterinary Research 45: 2062-2065.

[19] Griffin DW, Gregory CR, Kitchell RL (1989) Preservation of striated-muscle urethral sphincter function with use of a surgical technique for perineal urethrostomy in cats. Journal of the American Veterinary Medical Association 194: 1057-1060.

[20] McLaren IG (1988) Prepubic urethrostomy involving transplantation of the prepuce in the cat. Veterinary Record 122: 363 https://doi.org/10.1136/vr.122.15.363

[21] Mendham JH (1970) A description and evaluation of antepubic urethrostomy in the male cat. Journal of Small Animal Practice 11: 709721. https://doi.org/10.1111/j.1748-5827.1970.tb05575.x

[22] Bradley RL (1989) Prepubic urethrostomy. An acceptable urinary diversion technique. Problems in Veterinary Medicine 1: 120-127.

23. Baines SJ, Rennie S, White RS (2001) Prepubic urethrostomy: a long-term study in 16 cats. Veterinary Surgery 30: 107-113. https://doi.org/10.1053/jvet.2001.20327 
(2) 